\title{
A logistic study of the Brazilian airport model and its employment at the Tancredo Neves International Airport
}

\author{
Tadeu Hugo Ferreira Braga ${ }^{1}$ and Silva Jersone Tasso Moreira ${ }^{2 *}$ \\ ${ }^{1}$ Pontifícia Universidade Católica de Minas Gerais, Avenida Dom José Gaspar, 500, Prédio 03, Sala 114, Coração \\ Eucarístico, Belo Horizonte, Minas Gerais, Brazil, 30.535-091. \\ ${ }^{2}$ Universidade FUMEC, Avenida Afonso Penna, 3880, 1ํ Andar, Bairro Cruzeiro, Belo Horizonte, Minas Gerais, Brazil, \\ 30.130-190.
}

Accepted 12 July, 2010

\begin{abstract}
The objective of this article is the logistic study about the Brazilian Airport Model, justifying its importance and the impediments to the segment's development, especially with regards to the cargo movement. As development, it is possible to evaluate the differences between the concepts of an industrial airport and the airport-cities, as complementary requirements to the national development. As a case study, the Tancredo Neves International Airport (TNIA) in Belo Horizonte, in the State of Minas Gerais, is presented as an example for the development of the sector and its conceptual evolution, with proposals for its operations.
\end{abstract}

Key words: Brazilian Airport Model, industrial airport, airport-cities, economic development.

\section{INTRODUCTION}

The aviation sector and the Brazilian economy demand higher flights. The growth of air cargo is estimated at $6.1 \%$ a year for the two next decades, which will consume more aircrafts and will demand an adequate infrastructure for the airport terminal segment.

According to the studies that were carried out by the Operation Studies Nucleus, of the "Escola de Governo Professor Paulo Neves de Carvalho", and of the "Fundação João Pinheiro", using the Anac's data (2009), the airfreight sector transports $40 \%$ of the economic value of cargos in the world, which represents $8 \%$ of its total weight. This means that products with high aggre-gated value are transported in this sector.

Despite the merchandise's distribution in Brazil, the international commerce is centralized on the sea transport modal, with $92 \%$ of the cargo's activities going through ports; would this be the future of the transport sector? It is possible to observe this with the production tendency in adopting the flow of technology, instead of following

${ }^{*}$ Corresponding author. E-mail: tasso@fumec.br. Tel: (55) (31) 3269-5230. Fax: (55) (31) 3269-5231. the low aggregated value industrial model.

It is possible to say that the world is going towards logistic models, with the production accomplished according to the consumer's demands, adopting sophisticated sale's prediction methods, which confirms the existence of a new supply chain model (Tadeu, 2008). An example would be the productive capacity of the technology companies, from the moment that material resources' purchase is confirmed in any part of the world. Starting at this stage, it is possible to verify the existence of stocks for production, usually put available by the suppliers. You cannot justify storage of high value resources, to avoid losses and diminish risks (Bowersox, 2001).

However, these companies' production is decentralized and globalized, in order to take advantage of free trade areas; this is allied to the good economical performance around the world and the outsourcing aspects.

In this scenario, the airport is fundamental. The speed of the cargo's movement leads the companies to choose this modality; they make themselves more agile in the business and increase their profit.

According to the World Air Cargo Forecast (2007 to 2008), a study that was made by the Boeing aircraft manufacture (2008), the sector should be worried with 
the high prices of fuel that in average, represents $30 \%$ of the aviation's costs, with an agio of $42 \%$ in 2008 for the world's market. Even with this problem, the report shows that cargo air companies registered a growth of $3.1 \%$ during this period and a growth forecast of today's 1,780 cargo aircrafts to 3,500 in 2025.

In this scenario, the United States of America represents the largest market, with $28 \%$ of cargo movement done by air. However, Asia will contribute to the fast growth of this segment, due to the economic growth of $10 \%$ a year in China. The question to ask is: what about the Brazilian aviation market? What are its operational characteristics?

\section{THE BRAZILIAN AVIATION MARKET'S PANORAMA}

The Brazilian aviation market has its own particularities. Since 2005, Vasp stopped flying when its license was cancelled by the Civil Aviation Department (DAC), the former inspection agency, which was substituted by the Anac. The motives were related to the lack of payment to the suppliers, their operational high cost and the low occupation level in the planes of their flying routes.

Varig, the most traditional company in this segment in Brazil, was subdivided into several business groups, as result of their high level of debts. The maintenance division was sold to the Portuguese TAP, while the Variglog, their cargo subsidiary, was sold to a North-American investment fund for US $\$ 100$ million. The Varig brand that flew passengers, was bought by the Áurea Group (owner of Gol Intelligent Airway). The size of the old Varig can be summarized in a debt of $R \quad \$ 7.7$ billion to suppliers, debts with the Central Bank, Infraero, DAC and tax debits. The other US $\$ 70$ million were with reference to aircraft leasing (Anac, 2009).

For sometime, it was cogitated the union between Varig and TAM, with the help of the Brazilian govern-ment and the contribution of US $\$ 1.8$ million so that the company, then with its headquarters in the State of Rio Grande do Sul, could pay its debts and avoid bankruptcy.

When Gol Intelligent Airways entered the sector, the attention of the aviation specialists were directed to the low cost, low fares model that were implemented be the company in Brazil. With a modern fleet consisting of Boeing 737 family aircrafts, the company used a logistic model of high permanency of its airplanes in the air, with less time on the ground and with simpler board services than the competitors, which enabled them to reduce their fare prices. The result is that today, their domestic market share is $40 \%$.

Historically, the aviation market has had strong negative impacts due to heterodox economic plans, such as fare price freezing during the "Cruzado" Plan and the high cost of aviation kerosene, supplied exclusively by Petrobras. These factors caused Transbrasil's bankruptcy that, since 2001, opted to withdraw from the market. The company left a debt of $R \$ 1$ billion, mainly with its fuel suppliers.

Not so long ago, Ocean Air, now called Avianca, tried to bring Transbrasil back to life, with the idea of transforming it into a cargo company, but this idea was not approved by the federal government. Ocean Air, itself, carried out a dismissal program of 600 employees, which was motivated by the increase of the fuel's prices, resulting in the interruption of its expansion plan in 2008.

The government's actions in the aviation market are linked to the approval of the bankruptcy law, allowing the companies of this segment to discount their losses, as the result of economical plans in the past, until the bankruptcy is declared.

Since January of 2009 , the newly named, Azul, en-tered the national market. It is an enterprise that belongs to the businessman David Neelman (one of the ex-controllers of the north-American Jetblue, the creator of low costs, low fare in the world), with the support of national and international banks that are interested in the growth of the Brazilian airfreight sector.

In spite of all the data that was mentioned before, the perspectives for the aviation sector are positive. Most of the aircraft manufacturing companies, among them Boeing, Airbus and Embraer, have been producing new models as an answer to the airline companies' demand. Data from lata (2008) shows that, in this year's first semester, there was a growth of $9.4 \%$ in the occupancy rate, with an average of $74 \%$ and a possible growth of $14.9 \%$ in the numbers of flights in Latin America. This fact can be proved by the operation of new international flights, for example, that are flying out of the city of Belo Horizonte, in the State of Minas Gerais, to the following destinations: Portugal, with connections to other localities in the European Union (Lisbon - TAP); United States of America (Miami - American Airlines); Panama, with connections to North America, Central America and other destinations (Panama - Copa Airlines).

\section{Air cargo transport}

When evaluating the cargo transport sector, it is possible to understand that Brazil has a network of services and companies that are focused on this segment, with the participation of national and international companies.

According to data from Boeing (2008), the Brazilian market will follow the tendency of the world's market, with expected growth.

In spite of the expectations, there is a necessity to solve the existing problems. Data from the Ipea (2010) shows that, the Brazilian economy grew with $0.4 \%$ in 2009 , which represents a higher value of the Real and the devaluation of the dollar's quotation. Data from the Banco Central Bank (2010) indicates the existence a check account deficit, due to the facilities in the quotation of the national currency, in the import of capital assets, In

detriment to exporting. The ideal would be to have a balance between the Real and the dollar, in order to 
stimulate the international commerce. The impact is found in the small exporter, which has difficulty in accessing international markets and the air freight modal.

Another negative aspect is the interruption of the Federal Fiscal Revenue services that in the last years, has stopped its activities, in average, one hundred days a year, causing delays and incalculable losses to the companies in the international commerce segment.

According to Infraero's data (2009), the total of cargo transported during 2008 was of 185 thousand tons, being that before the end of 2009 , the volume that was registered reached the total amount of 210 thousand tons. This increase should be credited to the importation of machinery and products with aggregated value, besides the diversification of destines and products, such as the milk by-products (powder milk), hay, electric-electronic products, machines and other kinds of equipment, automobile products, medicines, among others.

\section{International companies}

The international companies that operate in the national territory carry out their operations mixing passenger transport with the idleness of their cargo holds, in the flights between countries and by companies that are only dedicated to cargo movement, according to the Anac (2009).

As a company that does not have aircraft specifically used for cargo transport, American Airlines transported to Brazil in 2008, 42 thousand tons, offering a volume of 2.6 million cubic meters in the whole world. Only the company's cargo division has three thousand employees in the world, having received the title of year's best airline company in the world, according to the Logistic and Rapid Delivery Association, during the annual Con-ference of Air Freight of 2008, in Orlando, Florida, in the United States of America. The company uses the Boeing models 777 and 767-300, with daily flights flying out of Guarulhos and with road connections to cities, such as, Belo Horizonte, Campinas, Curitiba, Florianópolis and Porto Alegre, flying to New York (John Kennedy Airport), Dallas and Miami.

Among the companies that are dedicated to transporting cargo, FedEx has been in Brazil since 1990, concentrating its operations in the Viracopos Airport, in Campinas. It has about 600 employees and five weekly flights to Memphis and Tennessee, both in the United States of America.

Another company that works in Brazil is UPS. They started their operation in 1989, through third parties, only having its own address in São Paulo in 1995. Flying out of Viracopos Airport, the company flies to 500 destines around the world, with a gross billing of US $\$ 47$ billion worldwide.

An important player of this segment is the German Lufthansa, which has been present in Brazil since 1956. One of the programs with the best results in this segment is the Business Partnership Program, created by the company by dividing the cargos, with the intention of achieving partnerships and as a consequence, strengthening its distribution network. Its routes respect the Frankfurt Airport as the main cargo storage and distribution center. In Brazil, the company's operations are concentrated in Viracopos and Guarulhos Airports, with daily flights to every part of the world, with a total of more than 500 destinations. Only in 2007, Lufthansa transported 21 thousand tons in the Brazilian market, with a hundred percent of efficiency in the delivery.

\section{National companies}

The national aviation market is not only exploited by big foreign companies. In Brazil, there are companies that operated with profit, respecting the signed contracts, the movement period of time, the services implicit quality and maintaining reasonable operational cost.

Among these companies, the Total Linhas Aéreas is an important agent in the Brazilian aviation market. With its headquarters in Belo Horizonte, the company transports, in average, 5 thousand tons of cargo per month, with flights to the south, southeast and north of Brazil. Currently, the company has three aircrafts model 727-200, with the capacity of 20 tons of cargo, through its Total Cargo Division.

Another important company is the ABSA that has gained relevance due to the economic problems registered in Venezuela. All the supply of cargos leaving Brazil, was of this company's responsibility, which operates with $\mathrm{DC}-10$ and 767-300 aircraft models, and that operates in other countries other that Venezuela, such as Chile, Mexico, Peru, Argentina and the United States, by means of partnerships with other embarking companies. In 2006, the ABSA registered an average of 20 thousand tons of transported cargo.

TAM announced in 2009, an investment of more than $\mathrm{R} \$ 30$ million, adopting a new name. The company will stop operating as TAM Express, being renamed TAM Cargo, with a new infrastructure in the domestic cargo terminals and the implementation of a new information technology in the whole country. In 2007, the company's total revenue was $R \$ 776$ million, with the expectation of growing in 2008, as a result of the purchase of new equipment, totalizing 123 aircrafts.

However, the biggest national aviation cargo agent is still Variglog. Even with all its financial and judicial problems, the company detains about $47 \%$ of the national market and $20 \%$ of the Brazilian international cargo destinations. Nowadays, Variglog's operations involve aircrafts such as the 757-200, with expansion plans for its route and aircrafts. All of the company's operations are centralized in the Galeão Airport.

Companies such as MTA and TAF operate with expressive results in Brazil and could not be left out of this research. 


\section{Cargo movement in Brazil}

The data about the cargo transportation in Brazil are interesting. According to Anac (2009), in its statistic annual report, the main source of transport revenue is the domestic market, with a value equivalent to $R$ \$ 940 million, compared with the international traffic, that registered R \$ 645 million, according to the 2008's data.

The composition to the segment's revenue comes from the cargo movement, representing $84 \%$ of the total, being completed by $13 \%$ of the mail company and $3 \%$ of charter services.

The analysis of Anac's data (2009) indicates that the operational costs of the companies in the national cargo segment have its largest concentration on the payment of fuel, around $34 \%$, followed by personnel salaries with $19 \%$ and others. Now, in the international market, the biggest costs are with the fuel at $26 \%$, followed by personnel with $13 \%$ and others. It is possible to observe that in the international freight the presence of exchange rates is a factor to be considered.

The concentration of the distribution of materials is in the southeast and north regions of the country, observing the cargo movement and air-mail. One of the interesting points of the cargo movement in Brazil is related to the main origins and destinations of the international traffic. Brazil sends most of its cargos to the United States, Germany, Chile, Portugal and Argentina. In counterpart, it receives most of its cargos from Germany, Argentina, United States, Chile and France, respectively.

In the domestic traffic, the main origins are the states of São Paulo, Federal District, Rio de Janeiro, Amazonas, Bahia and Paraná. The main destinies are the states of São Paulo, Federal District, Rio de Janeiro, Bahia and the Amazonas.

It is possible to identify the strong presence of the state of São Paulo and its economical participation in the air cargo segment, especially due to its production in the industrial sector of the region. Then, what is the importance of the concept of industrial airport for the national economy?

\section{INDUSTRIAL AIRPORT VS. AIRPORT- CITIES}

This item has as its objective to investigate the concepts about industrial airports and, a posteriori, the model of the airport-cities as a possible solution for the functionality of today's airports.

\section{Industrial airport}

The concept about industrial airport is associated with the development model that brings economical gains with stock of goods, transporting for the companies, and for the regions that adopt the airport structure as a logistics center and in the promotion of industrial areas with a strong technological appeal. Its origins are associated with the "Exporting Processing Zones (EPZ)", which were abandoned in the 90 s by the Fernando Henrique Cardoso's government, according to Tadeu (2008).

The beginning of the industrial airport concept is correlated with the appliance of a service network around the airports' terminals.

The first industrial airport authorized by the Federal Fiscal Revenue in Brazil, was the TNIA, in the metropolitan region of Belo Horizonte, with the signature of the authorizing declaration act in 2005. The airport was authorized to develop activities of stocking, exposition, demonstration, functioning tests, industrialization, maintenance and repair. The credentials given by the Federal Fiscal Revenue was the first step for the installation of companies in and around the airport, in specific areas for each company, where they can operate with a special regime of a custom's entrepôt for importing and exporting.

This procedure permits stock materials with the suspension of tax payments and the right to use the fiscal benefits relative to exporting. The Confins Airport has today around its area, companies such as: Jabil, Clamper, Maxtrack VMI, Mecan and Gol Linhas Aéreas Inteligentes' Maintenance Center. The second industrial airport in Brazil was Viracopos, in Campinas, which has its authorization declared in 2006.

Only the Gol's installations resulted in an investment of $\mathrm{R} \$ 15$ million to give the adequate conditions to its terminal.

The economy resulting by the initiative of the company in operating in the Confins Airport, was $5 \%$ in the maintenance costs of its fleet, that is about $R \$ 250$ millions a year, besides the revenue received from the maintenance services given to other aviation companies.

Gol's performance in Minas Gerais has produced 250 direct jobs and 750 indirect ones. By the agreement signed with the State Government, the company will have to maintain itself in the airport for at least ten years and do all custom work at the Confins Airport.

After Gol, several other aviation companies have started their operations in Minas Gerais and there are yet several studies and consults by other companies, which are interested in operating at the TNIA, due to the good practices and experiences that have been shown by the industrial airport concept that was implanted. However, what is the difference between the industrial airport concept and the airport-city concept?

\section{Airport-cities}

The idea of airport-cities is related to the formation of urban centers around the industrial airports, offering multivariable services and increasing the creation of jobs in the airport's region, according to Kasarda (2008). Having clusters with complementary activities, which are attracted to the region, these centers can be expanded in a ratio of up to $20 \mathrm{~km}$ around the airport, forming more 
ample metropolitan areas, according to the modern concept of "Airtropolis", that are to airport-cities as metropolitan centers are to urban centers.

It is, therefore, possible to identify two evolution levels of embryonic industrial airports: the airport-city, equivalent to a center of services that offer all the functions of a modern urban center around the airport terminal; and the Airtropolis, arterial network related to the whole metropolitan region, more complex and more ample, that develops itself because of the industrial airport economical potential.

The new services that will be offered at the airports include: restaurants, commercial centers, research centers, gyms, hospitals and even golf courses. Around it, it is still possible to install transport routes and communication fluxes, business offices, technological compounds, hotel networks and entertainment parks, industrial centers, free commerce zones and storage and supply logistic centers.

A classical example of an airport-city is Las Colinas, an urban center close to Dallas airport, Forth Worth (DFW), that has 12, 000 ac of extension, with an ample network of business offices, industrial spaces and service centers that included 13,300 homes, 3,700 hotel beds and more than 75 restaurants.

The changes in the organizing form of the airports, expresses an evolution in the functions that they carry out and in the ways of financing the airport's basic infrastructure, other than the traditional functionality of the airports. However, there are barriers that have to be overcome in the process of implementing this development model. The question is: which are the barriers?

\section{The barriers to the airport-city model}

The tributary question represents a considerable problem in implementing the airport-city model. After all, to attract companies, it will not only be necessary to offer logistic advantages, but also tax incentives, Kasarda (2008). The airport-city model guarantees that the companies will have tax free incentive when importing the components used in producing export products, according to the entrepôt's custom regime of the Normative Instruction number 241 of the Federal Revenue's Secretariat.

One of the advantages for the companies to come and install themselves in an industrial airport is that the exporting platforms will be created, in which the components will be free from importing taxes. The mechanism is something like of a free-trade zone, in which the manufacturers can produce without paying the components importing taxes. However, the difference is that, in the free-trade zone, the manufacturer can aggregate input resources from the national industries, in other words, include in the composition of their products, components supplied by Brazilian companies. In Brazil, the products manufactured in the free-trade zone end up also supplying the internal market, which would not be legally allowed in an industrial airport, for there is the requirement that, products that are made with imported components inside the airport zone have to be exclusively exported.

The TNIA was the first airport to be approved by the Federal Revenue to operate as an industrial airport, and is operating since August of 2006, with the promulgation of the edit number 44,301/06. Thus, companies that are installed in the international airport's area will have suspended the federal taxes for importing and exporting, but there still is not a clear definition about the suspension of the tax over Merchandise's Circulation and Services (ICMS) when purchasing raw material from the internal market. Even with these problems and in a joint effort of the federal, state and municipal governments together with the private initiative, before the end of 2009, we will know the norms that will discipline this special regime, suspension and/or economic custom entrepôt, more specifically the industrial airport.

Further, a case study about the Tancredo Neves International Airport (TNIA) in Belo Horizonte will be presented.

\section{CASE STUDY - TANCREDO NEVES INTERNATIONAL AIRPORT (TNIA)}

The TNIA is localized in the municipality of Confins, in the metropolitan area of Belo Horizonte $(\mathrm{RMBH})$, which started to be built in the decade of 1970 . This enterprise happened due to the diagnostic about the Carlos Drummond de Andrade Airport (Pampulha) that was saturated and could not support any longer, the intense growth of cargo and passengers' movement at the time. At the beginning, the idea was that Pampulha Airport was to be used for regional traffic, with smaller aircraft for shorter distances. However, this did not occur. Because of the precariousness of the access to the Tancredo Neves International Airport (TNIA), passengers preferred do fly using the flights based at the Pampulha Airport, economizing time and money, due the fact that the airport was qualified to operate national lines and not only the regional ones. Based on this scenario, the weak performance of the TNIA is justified.

According to Infraero (2009), the TNIA dealt with just over 4.7 million passengers and 26.7 thousand tons of cargo, being that its operational capacity is of 5 million passengers and 40 thousand tons of cargo. These numbers puts the airport as the eighth busiest one of the country, when considering the volume of passengers and the tenth busiest one considering the volume of cargo. It is known, however, that the demand for the metropolitan area of Belo Horizonte, computing the movement of the International Airport and the Pampulha Airport, is placed in the fifth place among the metropolitan areas with the largest air traffic.

The main effects of the TNIA's idleness on the state of Minas Gerais' economy, lies on the fact that the airport 
has produced a very small number of direct and indirect jobs, besides the lack of international connections, The air cargo of Minas Gerais is loaded in the airports of Rio de Janeiro and São Paulo. Due to this fact, the companies from Minas Gerais have lost their competitiveness, agility in their production and in the delivery of their products, while the state government has lost in tax collection.

Based on these data, the Tancredo Neves International Airport (TNIA) has, since 1998, presented proposed actions to transform it in a center for international commerce activities. These actions are directed to transform TNIA in an industrial airport, where investments will be made in infrastructure with the objective of making the airport's site adequate for industries to be installed. A second action is to make it more feasible for more international flights leaving from TNIA; a fact has been proven with the operations of TAP (Lisbon), Copa Airlines (Panama), American Airlines (Miami) and other advanced negotiations to other destinations.

The development of an industrial airport will generate a gradual growth of the cargo's volume, which will bring a bigger interest of the aviation companies. This will bring quality jobs and as consequence, the growth of the region's income. The next step would be the implementation of the city-airport model, being the first national model to stimulate the national economy, with the TNIA being an important hub of cargo and passengers transport.

It is necessary to considerer that there are no legal restrictions, since the TNIA is the first Brazilian airport to have a homologated environment license and which is recognized by national, state and municipal authorities. It is possible to visualize the Airforce base of Lagoa Santa, the municipalities of Vespasiano and Lagoa Santa, the Microelectronic Center and the MG-10 Highway.

The future projects for the TNIA involve the improvement of the accesses, the amplification of Gol Linhas Aéreas' aircraft maintenance center, amplification of the runways, cargo terminal and an ample development of a chain of public and private services. Therefore, the TNIA is a pioneer project in Brazil, visualizing the future of a national transport matrix, in comparison only with countries like the United States, Holland, Singapore, among others.

\section{CONCLUSIONS}

In this article, it was possible to understand that the Brazilian airports are in favorable operational conditions, when analyzed by the conditions of the past. The specific contributions of this study are associated with the observation of the concepts about the industrial airport model and its evolution to airport-cities. At the end, long term proposals were made, tied to the opportunities of this segment's activities, which will generate suggestions for future studies.

\section{REFERENCES}

Boeing (2008). http://www.boeing.com.

Bowersox DJ (2001) Logística Empresarial: The process of integrating the supply chain. São Paulo: Atlas.

Infraero (2009). http://www.infraero.gov.br.

Institute of Applied Economic Research (2010). http://www.ipea.gov.br.

International Air Transport Association (2008). http://www.iata.org.

Kasarda JD (2008). Kenan Institute of Private Enterprise .The University of North Carolina at Chapel Hill.

National Agencies (2010). http://www.bc.gov.br.

National Agency of Civil Aviation (2009). http://www.anac.gov.br.

Tadeu HFB (2008) Logística Empresarial Prospects and Opportunities. Belo Horizonte: Fundac. 